\title{
A Case Study: Enhancing the Learning Process and the Quality of the Students' Work in Online Courses Using Multiple High Impact Practices and Civic Strategies
}

\author{
Awatef A. Ben Ramadan ${ }^{1}$ \\ ${ }^{1}$ Department of Mathematics, Science, and Informatics, College of Professional Advancement, Mercer University, \\ Atlanta, Georgia, United States \\ Correspondence: Awatef A. Ben Ramadan, Department of Mathematics, Science, and Informatics, College of \\ Professional Advancement, Mercer University, 3001 Mercer University Drive, Atlanta, Georgia, United States.
}

Received: September 16, 2020

Accepted: February 9, 2021

Online Published: February 22, 2021

doi:10.5430/ijhe.v10n2p308

URL: https://doi.org/10.5430/ijhe.v10n2p308

\begin{abstract}
Background: Employing High Impact Practices (HIPs) in the curriculum will keep the students engaged and will boost their learning outcomes.

Study Aim: Explore the students' feedback on two HIPs practices and measure the impact of the studied HIPs on the course's outcomes.

Methodology: Two HIPs strategies were applied to the graduate students of an advanced online eight -week course. A cross-sectional study by conducting an online Survey-Monkey survey to assess the studied HIPs. The interventions were the group leadership and scaffolding the course's final project strategies.

Results and Discussion: $53 \%(\mathrm{n}=17)$ of students responded. 53\% very liked and liked the leadership group HIP. $82 \%$ found the leadership group HIP helpful to present and establish discussions with their classmates. 76.5\% either strongly agreed or agreed that the group leadership HIP helped them as presenters and discussion moderators, as well as in handling the weekly assignments. 52.94\% agreed and strongly agreed that the leadership HIP helped them, as an audience, to understand the curriculum and assisted them in handling the weekly assignments and projects. $94.12 \%$ agreed or strongly agreed that the dissemination of the final project's sections on the weekly assignments helped them understand and write the final project effectively. The average final project grades of the class under study was $97 \%$ in comparison to $90 \%$ of the same course the instructor taught in Spring 2018.
\end{abstract}

Conclusion: Introducing HIPs strategies will make the students feel that they owned the learning process and enhanced their creativity, self-confidence, and self-efficacy skills.

Keywords: online learning, high impact practices, civic strategies, learning quality

\section{Introduction}

In 2008, the Association of American Colleges and Universities (AAC\&U) published a book on High Impact Practices (HIPs). The book defined the various HIPs and discussed their importance in boosting and enhancing the learning achievements of non-traditional and underserved students (Kuh, 2008). The book gained the attention of higher education, and interested faculty and educational leaders started thinking about employing some HIPs in the curriculum and in the learning process itself to keep the students engaged and to boost their students' learning outcomes. Some colleges redesigned their students' learning experience around HIPs and other related active learning and social activities like service and civic learning strategies (Finley \& McNair, 2013; kuh, 2008; Kuh \& O'Donnell, 2013). HIPs defined by Kuh and his colleagues at the AAC\&U as, "active learning practices that promote deep learning by promoting student engagement" and "Achievement of deep learning, significant engagement gains, and positive differential impact on historically underserved student populations" (Kuh \& O'Donnell, 2013).

Our undergraduate and graduate informatics degrees of the department of mathematics, science, and informatics in the College of Professional Advancement at Mercer University has faced several learning and teaching challenges. Some of these challenges include entirely online degrees, courses are eight weeks long, weekly synchronous (virtual) meetings and intensive writing and project-based assignments, and most of the students are non-traditional. The main challenge is that those non-traditional African-American and Hispanic students should gain specific skills and meet 
the learning outcomes of the degrees' courses, and they are required to have intensive writing skills to handle and comprehend their capstone projects (Horn \& Carroll, 2006)

To increase student success and achievements, the students should be engaged in one HIP during each academic year (Kuh \& O'Donnell, 2013). In our informatics degrees, students are required to be involved in some HIPs experiences, such as service-learning and capstone projects, before graduation. We have tried to involve our students in further HIPs, in most of the degrees' courses, to increase student success. Now, our faculty are alert about the importance and the impact of establishment of more HIPs in their curriculum, and they have realized that HIPs are essential piece to attain all the degrees' assigned learning objectives by the students (AAC\&U, 2019; Brownell \& Swaner, 2009; Brownell \& Swaner, 2010; University of Wisconsin Eau Claire, 2019).

The investigator realizes the criticality of applying HIPs strategies to enhance the learning process and promote active interactions of the students. In the current paper, the investigator has assessed two HIPs, which she applied to one of her graduate courses. The first HIP was the group leadership practice, which is defined under the methodology section of this paper, and it belongs to the collaborative assignments and projects of Kuh's HIPs experiences (Kuh \& O'Donnell, 2013). The second HIP was scaffolding the course's final project and disseminating it over several weeks and it belongs to the intensive writing courses, a significant investment of time and effort by students over an extended time, and the frequent, timely, and constructive feedback Kuh's HIPs experiences (Kuh \& O'Donnell, 2013). The instructor applied two HIPs in an eight-week long online graduate course. She conducted a Survey Monkey survey to explore the students' feedback on both practices and to assess and measure the impact of the studied HIPs on the course's outcomes. The investigator used the students' grades and GPA to assess the impact of the studied interventions on the students' weekly assignments quality, on the timely submission of the completed final project by students, and on the final students' GPAs.

\section{Methods}

The investigator applied multiple HIPs strategies on the graduate students of an advanced course of the Master of Science in health informatics program, INFM 665 Clinical Decision Support Systems and Tele-health in Health Informatics. The study investigator was the instructor of the course during the study time. The course was an online, eight-week long course that included weekly virtual meetings lasting two hours. The investigator used Zoom conferencing software to meet weekly with the students. The students under study were all the enrolled 32 students in the INFM 665 class of the fall semester 2018.

\subsection{Study Design and Tool}

A cross-sectional study by conducting an online Survey Monkey survey of eight closed and Likert scaled questions, which was constructed by the study investigator, to assess the main two HIPs she applied in the class. The interventions, which assessed by the study investigator were the group leadership and scaffolding the course's final project strategies. The investigator announced the survey in the sixth week's virtual meeting of the class. She sent the survey link to all course students. Seventeen students out of a total of 32 students (53\%) responded to the survey.

\subsubsection{Studied HIPs Interventions Mechanism}

\subsubsection{Group Leadership HIP}

For every week of the course, a group of three or four students was assigned to prepare a PowerPoint presentation of ten slides or fewer on the week's assigned reading material to present in the class. The same group had to prepare at least five questions to ask the remaining students and had to moderate the discussion with the help of the instructor. Every student participated once in this active practice. In the last 45 minutes of every virtual meeting of the class, the instructor emphasized the most important points of the week's content, presenting her slides, videos, and case studies. Before she wrapped-up all the virtual meetings, the instructor asked her discussion questions to assess the students comprehending of the week's material and evaluate the students' readiness to answer the week's discussion, quiz, and/or writing assignment.

\subsubsection{Scaffolding the Course's Final Project}

The instructor scaffold the final project and divided it into six independent sections spread over the final five weeks of the eight weeks course. Figure (1) shows the final project's detailed sections. In the third week's virtual meeting, the instructor presented and discussed in detail the entire final project's sections, she also shared and discussed with the students all the rubrics that she assigned for the final paper and in-class presentation. The six sections were disseminated as table (1) shows. 
Table 1. Distribution of the Final Project's Sections over the Course Weeks

\begin{tabular}{lc}
\hline Final Project Section & The Course Week \\
\hline Sections I \& II & Week 4 \\
Section III & Week 5 \\
Section IV & Week 6 \\
Section VI & Week 7 \\
Section VII and Turn-in the completed final project & Week 8 \\
\hline
\end{tabular}

Section 1 - Choose a well-known and commonly used CDSS in healthcare.

Section 2 - Overview / Introduction

Define the problem has been solved by the chosen CDSS and search the current literature to write your background on the chosen CDSS and the health problem it is solving.

Section 3 - The Model

Describe in detail the underlying model and framework (structure) for the chosen CDSS: knowledgebased (if-then rules or probabilities) supervised or unsupervised learning CDSS: if supervised which kind of classifier the CDSS following, if unsupervised is it clustering or not (in detail).

Draw a sketch of the clinical workflow after your CDSS integrated to the clinical workflow.

Classify the chosen CDSS application's modality/ies (alarm, test ordering, medication ordering, procedure ordering, calculator, diagnosis aiding, treatment guiding, .....etc).

List out performance measures and outcomes that you expect your CDSS application to improve.

\section{Section 4- Risk Assessment Tool}

After the IT professional implemented a CDSS to the clinical setting within a healthcare facility, there are many failure modes could be expected or assumed by the If implementers.

Using the spread sheet (HFMEA hazard analysis sheet), please assess the risk of implementing your CDSS in the clinical setting and recommend solutions for these failure modes.

\section{Section 5- Evaluation}

Describe the methods that can be used to evaluate your CDSS application (what is/are best ways of evaluation strategies to assess the system? And why?)

Based on your expected evaluation results, redraw your workflow Diagram and describe your expected effective workflow.

\section{Section 6 - Discussion and conclusion}

This can be a catchall section for all other aspects of your project like project assumptions, limitations and recommended future work to solve the targeted problem.

\subsection{Statistical Analysis}

Figure 1. The Final Project's Detailed Sections

The investigator used the Survey Monkey statistical tools to develop and present the results graphs and figures.

\section{Results}

The demographic distribution of the Survey Monkey participants, as figures (2) and (3) show that nine (52.94\%) of the participants were 35-44 years old, six students (35.29\%) were 25-34 years old, one student from the 45-54 years old category, and another student from 18-24 years old age group.

Eleven students $(64.71 \%)$ of the participated students were African-American, 2 students $(11.76 \%)$ were from the Hispanic or Latino race group, two students (11.76\%) were Asian or Asian- American, one student (5.88\%) was white, and another student (5.88\%) marked her from the "Another Race" group. 


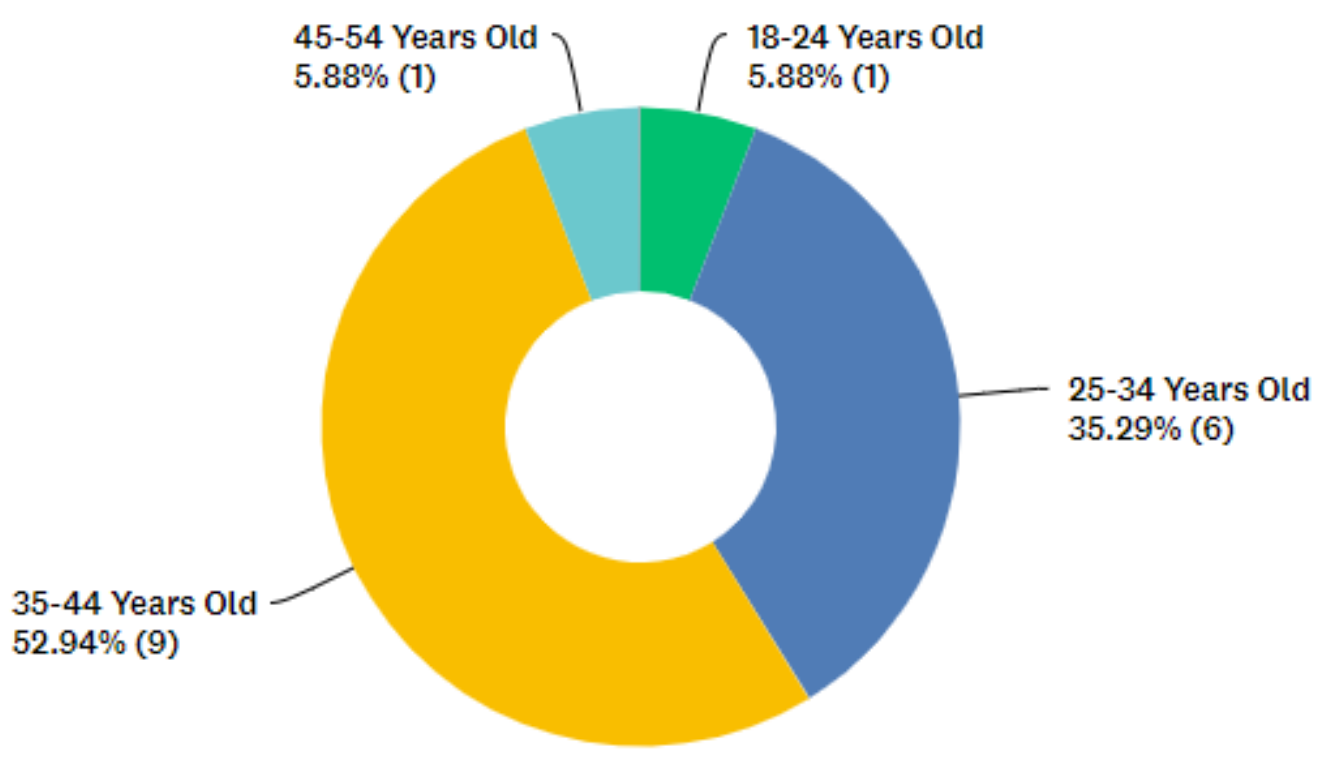

Figure 2. Age Distribution of the Study Participants

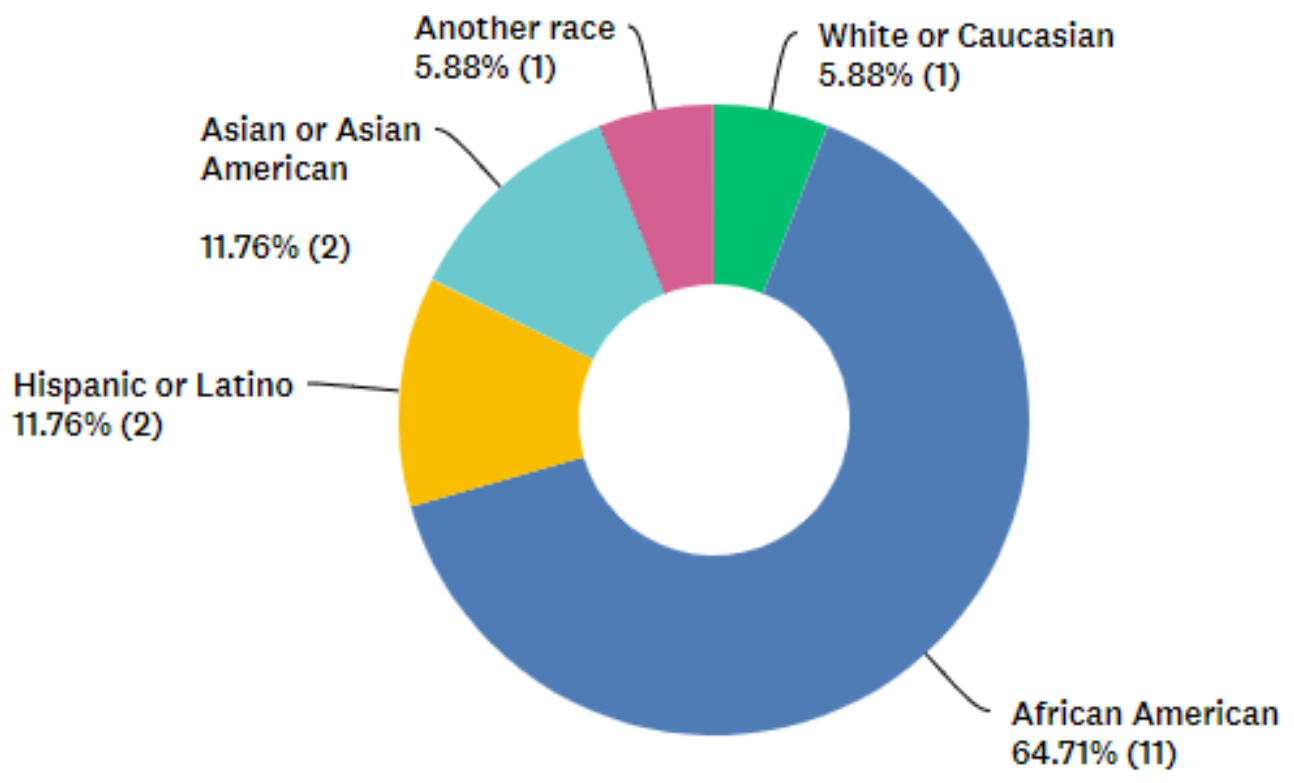

Figure 3. Race Distribution of the Study Participants

Figure (4) demonstrates the response of the participated students to the survey question "How do you like the leadership group experience?". As the figure shows, nine participants (53\%) very liked and liked the leadership group HIP. Five students (29\%) showed a neutral reaction to the question. Three students (18\%) did not like the strategy. 


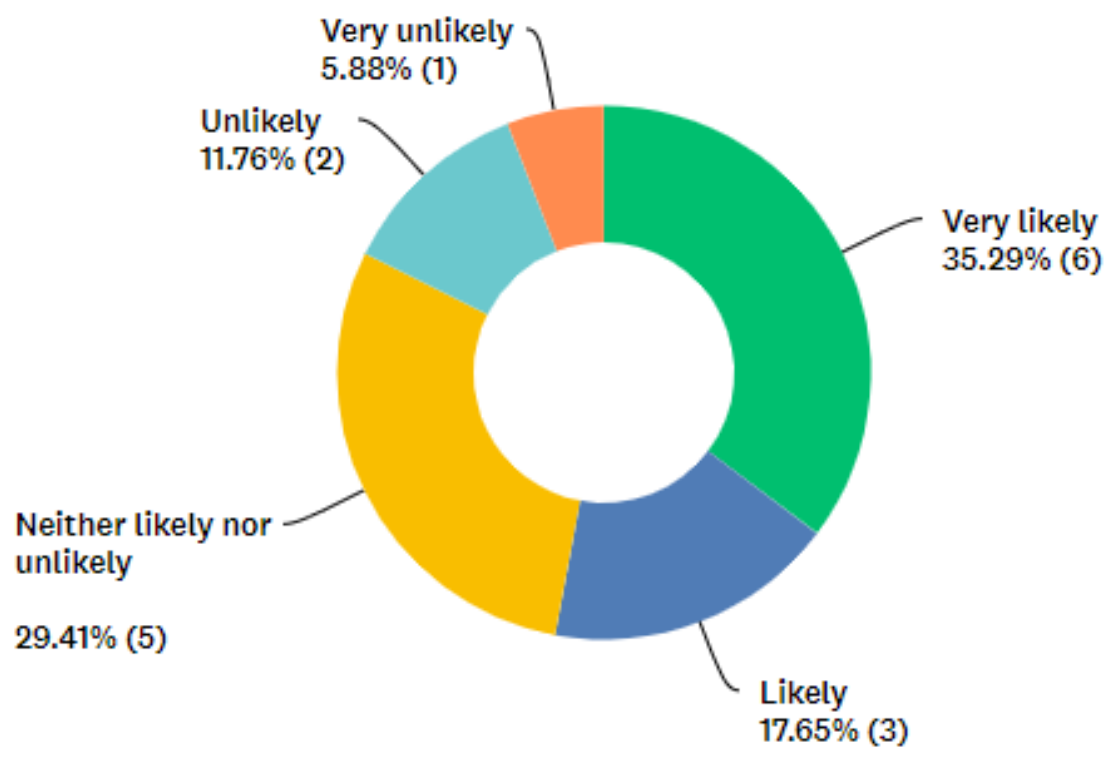

Figure 4. The Response of the Study Participants to the Survey Question, "How Do You Like The Leadership Group Experience?"

The following graph, Figure (5), shows the results of the students' answer on the survey question, "How much did the experience help you to be confident in virtually presenting and moderating a discussion with the audience?". The results demonstrate that one student agreed that the experience was very helpful in making that student confident in presenting and moderating discussion virtually. Fourteen students $(82 \%)$ found the experience was helped them to present and establish discussions with their classmates. Only two students (12\%) found the experience had too little help in boosting their confidence while they were virtually presenting and conducting discussions.

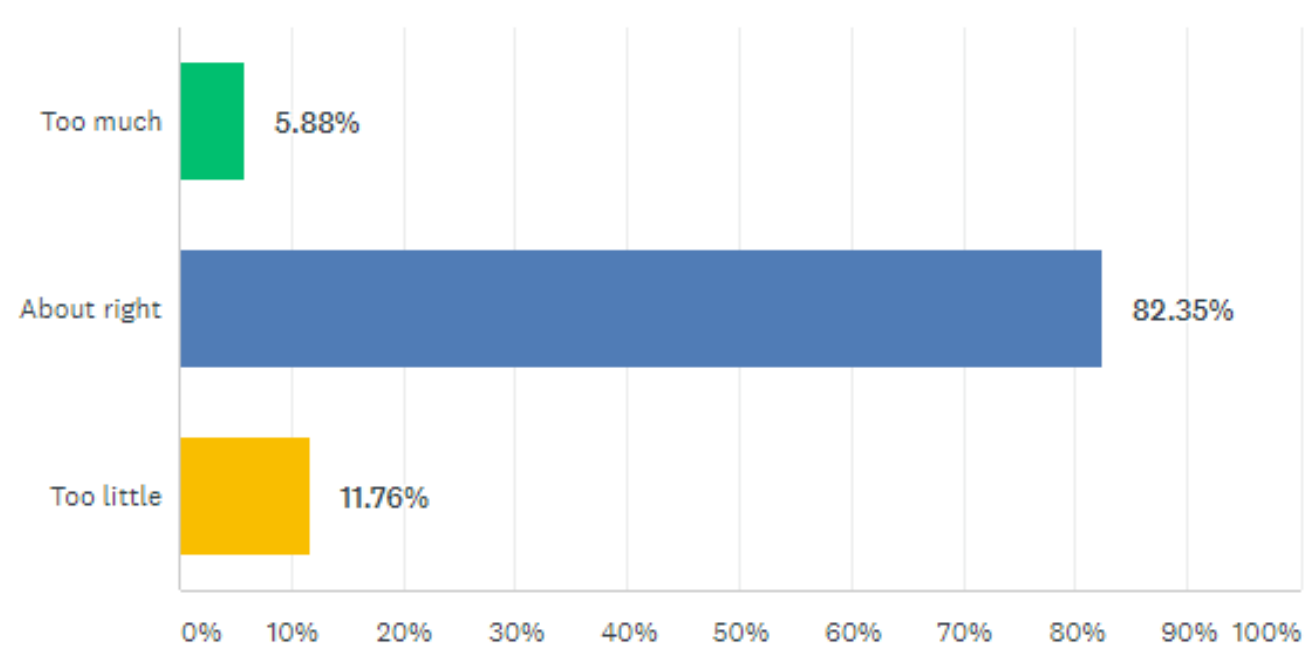

Figure 5. The Response of the Study Participants to the Survey Question, "How Much Did The Experience Help You To Be Confident In Virtually Presenting And Moderating Discussion With Audience?" 
Figure (6) reveals the results of student answers on the survey question, "How much do you agree that this active learning experience had helped you as a presenter in understanding the course's material and in answering the weekly assignments?". Thirteen students (76.5\%) either strongly agreed or agreed that the group leadership HIP helped them as presenters and discussion moderators to master the course's material, as well as in handling the weekly assignments. Two students responded to the question neutral (12\%). Two students $(12 \%)$ found that the experience had not helped them in understand the course's content and said it was not supportive in answering the weekly assignment questions.

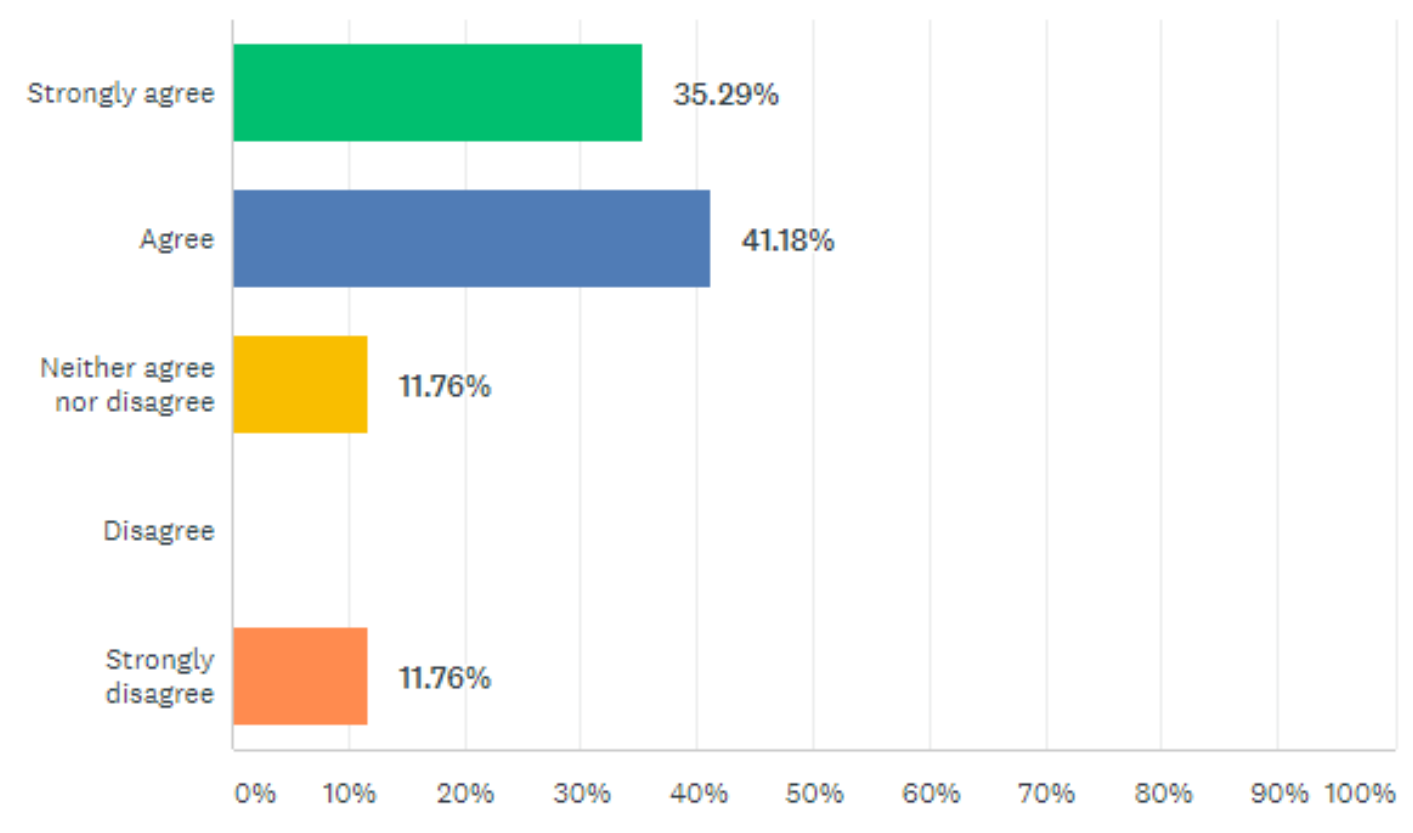

Figure 6. The Response of the Study Participants to the Survey Question, "How Much Do You Agree That This Active Learning Experience Had Helped You As Presenter In Understanding The Course's Material And In Answering The Weekly Assignments?"

The following chart shows the results of the participated students' response to the survey question of "How much do you agree that this active learning experience had helped you as an audience in understanding the course's material and in answering the assignments?". Nine students (52.94\%) agreed and strongly agreed that the leadership HIP helped them, as an audience, to understand the curriculum and assisted them in handling the weekly assignments and projects. Six students (35.29\%) responded neutrally to the question; they were neither agreed nor disagreed on the question's content. Two students (11.76\%) strongly disagreed with the questions' statement. 


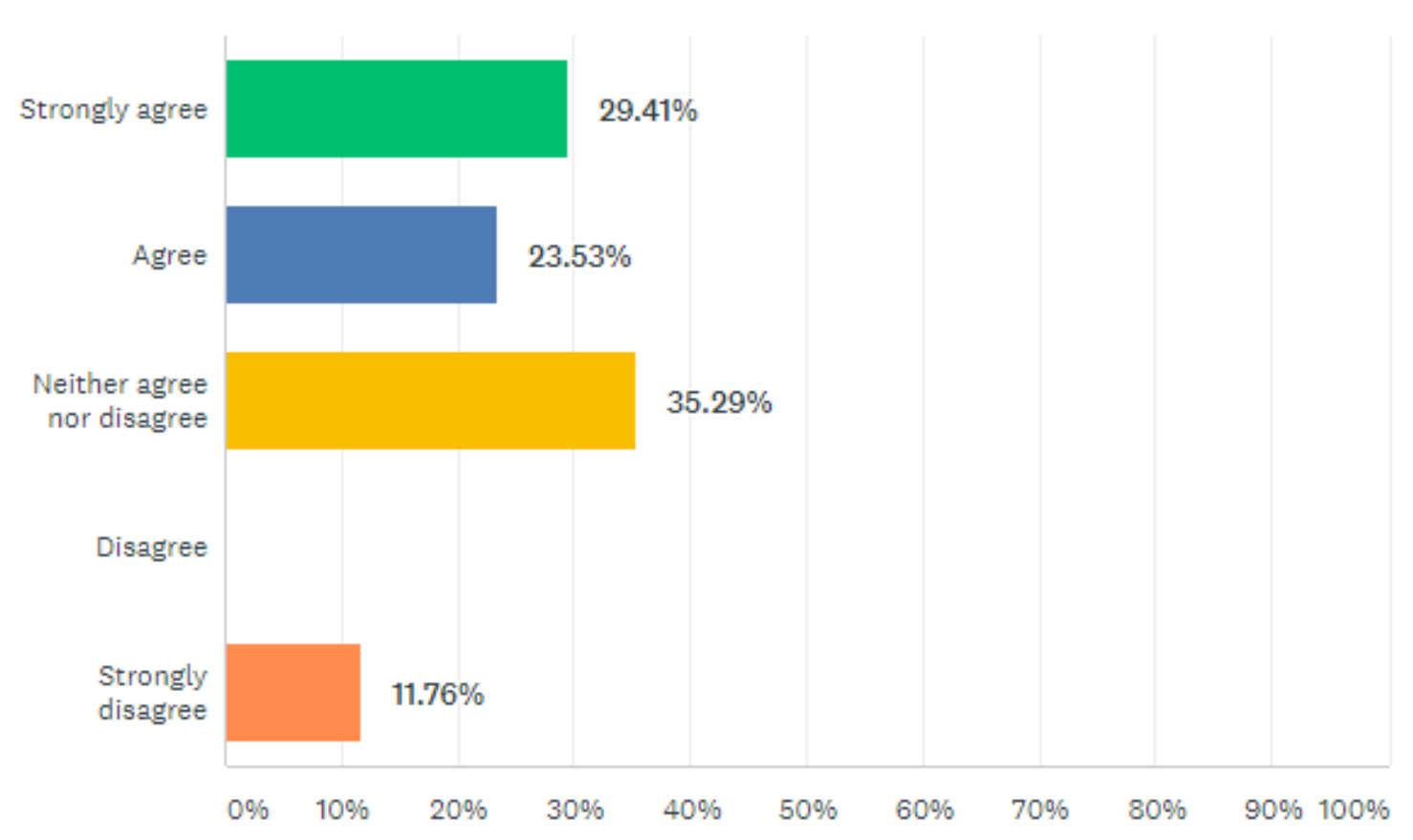

Figure 7. The Response of the Study Participants to the Survey Question, "How Much Do You Agree That This Active Learning Experience Had Helped You As An Audience In Understanding The Course's Material And In Answering The Assignments?"

In response to the last survey question, 16 students $(94.12 \%)$ agreed or strongly agreed that the dissemination of the final project's sections on the weekly assignments helped them understand and write the final project effectively. One student $(5.88 \%)$ disagreed with the question's statement. 


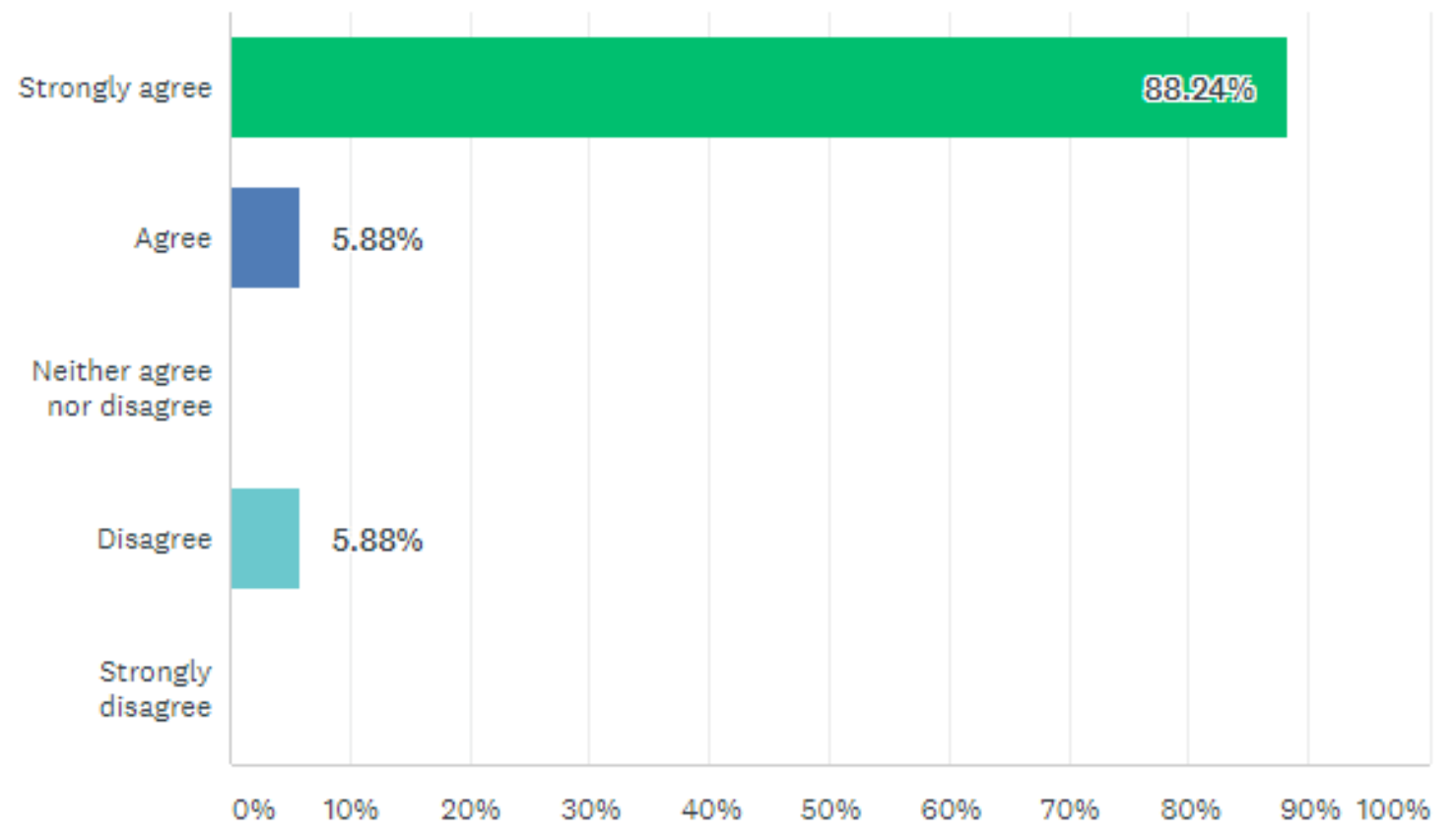

Figure 8. The Response of the Study Participants to the Survey Question, "How Much Do You Agree that the Dissemination of the Final Project's Sections on The Weekly Assignments Helped You in Understanding and Effectively Writing the Final Project?"

The investigator used the weekly assignments' grades and the course's final GPAs of the students to assess the active learning HIPs interventions applied in the class. In the discussion section, the investigator will compare the Survey Monkey results to the students' actual achievements, which are the weekly grades and the class's GPAs in the course.

\section{Discussion}

Before she started the study, the investigator made two assumptions regarding the two interventions she adopted for this research to support the INFM665 course's study objectives. Those assumptions were:

1. By applying the group leadership strategy, the assigned student groups will be responsible on covering the weekly reading assignment, will have enough knowledge about the week's material, will turn-in good quality assignments, and will feel encouraged to ask questions and interact with the instructor and the peer students.

2. By scaffolding the final project and divide it over five weeks of the eight-week class, the students will be able to deeply and adequately understand and master the final project sections, will have enough time to write and turn good quality final project, and will get feedback on their weekly assignments by the instructor. The students will consider the instructor feedback before they submit the final project at the end of the course, and this will enhance the quality of the final projects.

The demographic distribution of the Survey Monkey participants reflected the class's demographic distribution: most of our students were non-traditional students in the 35-44 years old age group, and more than $90 \%$ of the students were African-American.

As the investigators assumed, most of the surveyed students liked and very liked the leadership group HIP. The results also were supported by evidence that shows the effectiveness of the leadership group, which is belonging to the collaborative assignments and projects HIPs category by Kuh, on the students' satisfaction and achievements (Kuh \& O'Donnell, 2013). About a third of the students responded neutrally and their response was they neither like nor unlike the leadership group HIP. Based on the weekly grades of the students, the instructor found that all the weekly assigned student groups had higher grades on their assignments for the weeks they led the class than most of the audience students, and they self-assuredly defended their ideas in the discussion forum for those weeks. The 
instructor concluded that even if they were neutral in their response, the students benefited from the strategy and the strategy helped them understand the material and confidently discuss their peers during the weeks they led the class (Brownell \& Swaner, 2009; Finley \& McNair, 2013; Kilgo, Sheets, \& Pascarella, 2015; Price \& Tovar, 2014).

Most of the students agreed that the leadership group HIP helped them to be confident while they were presenting and moderating the discussion in the virtual space. This result meets the investigator's assumptions made before the study. The instructor found that the students read carefully the weekly assigned readings. In addition, the students were able, as groups, to summarize the weekly assigned material into few slides that include the most important information and were able to support their presentations with adequate evidence. Every week's team was able to develop reasonable questions to start the discussion with their audience peers. It was a challenge to adapt and introduce this HIP to our non-traditional students, who have social and other challenging difficulties outside the classes (family, financial obligations, full- or part-time advanced jobs, etc.) (Brownell \& Swaner, 2009; Finley \& McNair, 2013; Kilgo et al, 2015; Price \& Tovar, 2014). The results showed that those students liked the strategy and according to the instructor supervision and monitoring, the students successfully collaborated through emails, Mercer Canvas, and Zoom conferencing software and were capable of turn-in in high-quality presentations and assignments (McLoughlin \& Luca, 2002).

As the results show, the audience students also benefited from the leadership group HIP. Most of the students agreed that this active learning experience had helped them, as an audience, in understanding the course's material and in answering the weekly assignments. The investigator assumed that the active interaction and discussion, which happened each week amongst the students in the class, made the audience students able to understand the weekly material and helped them in answering the assignments.

As the study results show, most of the students agreed or strongly agreed that the spreading of the final project's sections on the weekly assignments assisted them in completing and mastering the final project. This meets the supposition the investigator made for the study. The students were enabled to comprehend the disseminate final project sections successfully because they started working on their final project very early and every week they had to answer a section of the broken down project (Dennen, 2004; Northern Illinois University's Faculty Development and Instructional Design Center, 2008). Every week's section was related to the curriculum the student learned in that week, and this enabled the students to respond clearly and adequately to the assigned section. The weekly instructor comments and feedback on the weekly assignments helped the students to correct their mistakes and improve their assignments" quality. The instructor revealed a huge improvement in the quality and completeness when she compared the weekly answered sections of every student to the same sections that were included in every student's final paper. The students considered the instructor's comments and completed missed assignments before they turned in their final papers. The final project scaffolding enhanced the final projects' quality, completeness, and timeliness. The study proves that following this strategy has been very successful in eight-week online courses. The investigator compared the average final project grades of the class under study and the same course the instructor taught in Spring 2018 and found that the average final project grade of this cohort (97\%) was better than the average final project grade of the previous class's cohort $(90 \%)$. The current literature also shows that scaffolding final projects could inspire and enhance students, lessen assignment complexity, offer structure and increase student success (Alibali, 2006; Hogan \& Pressley, 1997; Van Rooij, 2009). Scaffolding the final project into sections could support the students as they seek to comprehend the course's concepts and tasks effectively and efficiently, and the scaffolding further improves the instructor-students interaction and communication (Alibali, 2006; Hogan \& Pressley, 1997; Van Rooij, 2009).

\section{Conclusion}

Assigning groups of the class students to develop teaching material to share with their peers at the virtual meeting time, made the students feel that they owned the learning process and enhanced their creativity, self-confidence, and self-efficacy skills. The current literature showed that the best instructional and teaching choices are those made by the students so they feel that they possess them (Leahy, Lyon, Thompson \& Wiliam, 2005; Stigging, 2008). The investigator found that the group leadership HIP challenged the students and made them interact successfully with the other group members and turned creative group projects used the assigned readings and additional sources through different online tools (YouTube videos, journal articles, related websites material). The studied strategy encouraged our non-traditional students to face their learning challenges and positively influenced their assignments quality and overall course success.

To enable students to achieve the courses' learning outcomes, we recommend that the instructors need to develop creative teaching HIPs that could engage the students actively in the learning process. Such strategies could enable them to understand the curriculum and to make them cognitively realize how they could attain the assigned learning 
objectives for the courses. We encourage that the instructors should give the students motives and opportunities to actively control and lead the learning process (Brookhart, Moss \& Long, 2009). We also recommend that these active learning strategies be constrained and guided by the instructors to protect the learning process from unneeded misleading and students' over control (Brookhart et al, 2009).

Scaffolding the courses' final projects could facilitate strong collaboration between the students and the course instructors, and scaffolding could also support the students' self-assessment towards the courses' objectives. Breaking down the final projects into equal sections disseminated over the course length enables frequent communication and feedback between the students and their instructors, and this will support the completeness and timeliness of the final project.

In summary, by applying and assessing the HIPS we could measure and assess the HIPs' input and impact on the students' learning outcomes and retention (AAC\&U, 2019). Based on the strong evidence that has built from the current teaching literature, the HIPs could increase the non-traditional students' involvement, preservation, success, and could increase the students' confidence and self-efficacy (AAC\&U, 2019; Finley \& McNair, 2013).

\section{Acknowledgement}

The study funded by the professional development fund of the Department of Mathematics, Science, and Informatics/ College of Professional Advancement at Mercer University. The publication was a course-based teaching research and the content is exclusively the responsibility of the author.

\section{Declaration of conflicting interests}

There is no conflicting interest to declare.

\section{References}

Association of American Colleges \& Universities (AAC\&U). (2019). High Impact Practices. Retrieved from: https://www.aacu.org/resources/high-impact-practices

Association of American Colleges \& Universities (AAC\&U). (2019). Assessing High-Impact Learning for Underserved Students. Retrieved from: https://www.aacu.org/assessinghips

Alibali, M. (2006). Does visual scaffolding facilitate students' mathematics learning? Evidence from early algebra. Retrieved February, 13, p.2016.

Brookhart, S. M., Moss, C., \& Long, B. A. (2009). Promoting student ownership of learning through high-impact formative assessment practices. Journal of MultiDisciplinary Evaluation, 6(12), 52-67. ISSN 1556-8180.

Brownell, J. E., \& Swaner, L. E. (2009). High-impact practices: Applying the learning outcomes literature to the development of successful campus programs. Peer Review, 11(2), 26. Retrieved from: https://search.proquest.com/docview/216602278?pq-origsite=gscholar\&fromopenview=true

Brownell. J., \& Swaner, L. (2010). Five High-Impact Practices: Research on Learning Outcomes, Completion, and Quality. Washington, DC: Association of American Colleges and Universities, 2010.

Dennen, V. P. (2004). Cognitive apprenticeship in educational practice: Research on scaffolding, modeling, mentoring, and coaching as instructional strategies. Handbook of research on educational communications and technology, 2(2004), 813-828. Retrieved from: http://faculty.weber.edu/eamsel/Classes/Projects\%20and\%20Research\%20(4800)/Teaching\%20and\%20Learnin g/Dennen\%20(2004).pdf

Finley, A., \& McNair, T. (2013). Assessing underserved students' engagement in high-impact practices. Retrieved from:

https://vtechworks.lib.vt.edu/bitstream/handle/10919/87004/AssessingUnderservingStudents.pdf?sequence=1\&i sAllowed=y

Hogan, K., \& Pressley, M. (1997). Scaffolding student learning: Instructional approaches and issues. Cambridge, MA: Brookline Books.

Horn, L., \& Carroll, C.D. (2006). How 4-year college graduation rates vary with selectivity and the size of low-income enrollment (NCES 2007-161). Washington, DC: National Center for Education Statistics.

Horn, L. (2006). Placing College Graduation Rates in Context: How 4-Year College Graduation Rates Vary with Selectivity and the Size of Low-Income Enrollment. Postsecondary Education Descriptive Analysis Report. 
NCES 2007-161. National Center for Education Statistics. Retrieved from: https://files.eric.ed.gov/fulltext/ED494020.pdf

Kilgo, C.A., Sheets, J. K. E., \& Pascarella, E. T. (2015). The link between high-impact practices and student learning: Some longitudinal evidence. Higher Education, 69(4), 509-525. https://doi.org/10.1007/s10734-014-9788-z

Kuh, G. D. (2008). Excerpt from high-impact educational practices: What they are, who has access to them, and why they matter. Association of American Colleges and Universities, 14(3), 28-29. Retrieved from: https://apps.weber.edu/wsuimages/oie/Support\%20Documents/Kuh_HighImpactActivities.pdf

Kuh, G.D., O'Donnell, K., \& Reed, S. D. (2013). Ensuring quality \& taking high-impact practices to scale. AAC \& U, Association of American Colleges and Universities.

Leahy, S., Lyon, C., Thompson, M., \& Wiliam, D. (2005). Classroom assessment: Minute by minute, day by day. Educational Leadership, 63(3), 18-24. Retrieved from: https://www.rbteach.com/sites/default/files/classroomassessment-minute-by-minute-day-by-day.pdf

McLoughlin, C., \& Luca, J. (2002). A learner-centred approach to developing team skills through web-based learning and assessment. British Journal of Educational Technology, 33(5), 571-582. https://doi.org/10.1111/14678535.00292

Northern Illinois University, Faculty Development and Instructional Design Center. (2008). Instructional Scaffolding to Improve Learning. Retrieved from: https://www.niu.edu/facdev/_pdf/guide/strategies/instructional_scaffolding_to_improve_learning.pdf

Price, D. V., \& Tovar, E. (2014). Student engagement and institutional graduation rates: Identifying high-impact educational practices for community colleges. Community College Journal of Research and Practice, 38(9), 766782. https://doi.org/10.1080/10668926.2012.719481

Stiggins, R. J. (2008). Student-involved assessment FOR learning. Upper Saddle River, NJ: Pearson Merrill Prentice Hall. Retrieved from: http://downloads.pearsonassessments.com/ati/downloads/tip-pub.pdf

University of Wisconsin Eau Claire. (2019). High Impact Practices: Active Learning Practices. Retrieved from: https://www.uwec.edu/acadaff/academic-master-plan/high-impact-practices/

van Rooij, S. W. (2009). Scaffolding project-based learning with the project management body of knowledge (PMBOK®). Computers \& Education, 52(1), 210-219. Retrieved from: https://doi.org/10.1016/j.compedu.2008.07.012

\section{Copyrights}

Copyright for this article is retained by the author(s), with first publication rights granted to the journal.

This is an open-access article distributed under the terms and conditions of the Creative Commons Attribution license (http://creativecommons.org/licenses/by/4.0/). 